\title{
Functional properties of neem oil as potential feedstock for biodiesel production
}

\author{
P. Bhandare ${ }^{a *}$, G. R. Naik \\ Department of Biotechnology, Gulbarga University, Gulbarga - 585106, Karnataka, India \\ ${ }^{a, b * E-m a i l ~ a d d r e s s: ~ p r i t h v i . e 87 @ g m a i l . c o m, ~ g r n a i k 123 b i o t e c h @ g m a i l . c o m ~}$
}

\begin{abstract}
Fossil fuel resources are decreasing daily while biodiesel fuels are attracting increasing attention worldwide as blending components or direct replacements for diesel fuel in vehicle engines. In this experiment the seed oils of 30 Neem (Azadirachta indica. A. juss) biotypes were screened and evaluated for their physio-chemical parameters for oil content, biodiesel yield, density, viscosity, iodine value, free fatty acid and saponification value. Hence the neem seed oil tested in this current study could be the potential sources of raw material for biodiesel production.
\end{abstract}

Keywords: Azadirachta indica; seed oil; biodiesel; physio-chemical parameters; feedstock

\section{INTRODUCTION}

Biodiesel is gaining increasing acceptance in the market as an environmental friendly alternative diesel fuel (Jidon Janaun et al. 2010). It is non-toxic, biodegradable, and free of sulphur or any carcinogenic compounds (Demirbas, 2007). The demand and cost of edible oils prevents its use in the production of biodiesel. So, a large variety of plants that produce non-edible oils are considered for biodiesel production. In India, there are several non-edible oil seed species such as Jatropha curcas (Jatropha), Pongamia pinnata (Karanja), Azadirachta indica (Neem), Madhuca indica (Mahua) etc., which could be utilized as a source for production of oil (Vuppaladadiyam et al., 2013) and can be grown in large scale on non-cropped marginal lands and waste lands. Fatty acid profiles of seed oils of 75 plant species having $30 \%$ or more fixed oil in their seed/kernel were examined (Mohibee, 2005), in which Azadirachta indica, Calophyllum inophyllum, Jatropha curcas and Pongamia pinnata were found to be most suitable for use as biodiesel and they meet the major specification of biodiesel standards of USA, Germany and European Standard Organization.

Neem (Azadirochta indica A. Juss) is a native Indian tree well known for its medicinal features. Most of the parts such as leaves, bark, flower, fruit, seed and root have applications in the field of medicine. It is an evergreen tree related to mahogany, growing in almost every state of India, South East Asian countries and West Africa (Muthu et al., 2010). It grows in drier areas and in all kinds of soil. It contains several thousands of chemicals which are terpenoids in nature. A mature neem tree produces 30 to $50 \mathrm{~kg}$ fruit every year and has a productive life span of 150 to 200 years (Ragit et al., 2011). It has the ability to survive on drought and poor soils at a very hot temperature of $44^{\circ} \mathrm{C}$ and a low temperature of up to $4^{\circ} \mathrm{C}$, and its high oil content of 39.7 to $60 \%$ (Ragit et al., 2011). In recent years there are growing 
concerns about the utility of neem oil as a source for biodiesel production in order to generate alternate source of energy. This is mainly due to the suitability of oil derived from neem seeds for biofuel purposes. Neem comprises mainly of triglycerides and large amounts of triterpenoid compounds. It contains four significant saturated fatty acids, of which two are palmitic acid and two are stearic acid. It also contains polyunsaturated fatty acids such as oleic acid and linoleic acids (Muthu V et al., 2010). The quality of oil in terms of its fatty acid composition is very important. The current studies on the fatty acids distribution of neem oil and physicochemical properties of oil viz., oil content, biodiesel yield, density, viscosity, iodine value, free fatty acid and saponification value indirectly influence the quality of oil for biodiesel production. However, such studies are limited in neem oil which thus warrants systematic investigation. Hence studies were carried out on physic-chemical characterization of various neem genetic resources.

\section{MATERIALS AND METHOD}

\subsection{Collection and Characterization of neem seeds}

Thirty different neem biotypes were collected from the different parts of Bidar, Gulbarga, Raichur and Zaheerabad districts (Table 1). Biotypes were screened on the basis of physical appearance and oil-mass solidification. Seeds were inspected and manually cleaned to avoid foreign matter and physical properties such as seed weight, oil content and biodiesel content were determined.

Table 1. Characterisation of morphological and some chemical properties of neem plant.

\begin{tabular}{|c|c|c|c|c|}
\hline Provenance & $\begin{array}{c}\text { No. of tress } \\
\text { studied }\end{array}$ & $\begin{array}{c}\text { Fruit weight of 10 seeds } \\
(\mathbf{g m})\end{array}$ & $\begin{array}{c}\text { Oil content } \\
(\mathbf{\%})\end{array}$ & $\begin{array}{c}\text { Biodiesel } \\
\text { Content (\%) }\end{array}$ \\
\hline Bidar & 8 & 5.1 & 31.5 & 60 \\
\hline Gulbarga & 5 & 6.8 & 43 & 85 \\
\hline Raichur & 2 & 5.3 & 38 & 65 \\
\hline Zaheerabad & 15 & 7.3 & 40.5 & 78 \\
\hline
\end{tabular}

\subsection{Neem seed preparation for oil extraction}

The cleaned seeds were sun dried in the open, until the casing splits and sheds the seeds. The seeds were further dried in the oven at $60{ }^{\circ} \mathrm{C}$ for $7 \mathrm{hrs}$ to a constant weight in order to reduce its moisture content, which was initially at about 5 to $7 \%$. The separation of the shell from the nibs (cotyledon) was carried out using tray to blow away the cover in order to achieve very high yield. Mortar and pestle were used to crush the seeds into a paste (cake) in order to weaken or rupture the cell walls to release castor fat for extraction (Crentsil Kofi Bempah et al. 2011).

\subsection{Neem oil extraction}

$150 \mathrm{ml}$ of normal hexane was poured into round bottom flask. $20 \mathrm{~g}$ of the sample was placed in the thimble and was inserted in the centre of the extractor. The Soxhlet was heated at $60 \mathrm{oC}$. When the solvent was boiling, the vapour rises through the vertical tube into the condenser at the top. The liquid condensate drips into the filter paper thimble in the centre, 
which contains the solid sample to be extracted. The extract seeps through the pores of the thimble and fills the siphon tube, where it flows back down into the round bottom flask. This was allowed to continue for 30 minutes. It was then removed from the tube, dried in the oven, cooled in the desiccators and weighed again to determine the amount of oil extracted. Further extraction was carried out at 30 minutes interval until the sample weight at further extraction and previous weight becomes equal. The experiment was repeated for different weights of the sample, 35, 40 and $50 \mathrm{~g}$. The weight of oil extracted was determined for each 30 minutes interval. At the end of the extraction, the resulting mixture (miscella) containing the oil was heated to recover solvent from the oil. Then, the following physicochemical parameters were estimated according to K. C. Verma et al. 2014.

Transesterification: Biodiesel produced by transesterification by alkali process as it results in high purity and yield of the biodiesel product in a short time. Methyl esters of fatty acids were prepared by the procedure described in Singh, Kumar, and Sethi (2006). The yield of methyl esters was calculated using the following formula:

$$
\text { Yield of methyl esters }(\%)=\frac{\text { Grams of methyl esters produced }}{\text { Grams of oil used in reaction }} \times 100
$$

Density of Oil: Density of the sample is directly proportional to unsaturation and inversely to molecular weight. First, the empty cylinder was weighed, which was further filled with the sample and measured again.

Viscosity of oil: Viscosity is a measure of internal friction. It is an essential property which affects atomization of fuel and mixing of air and fuel in the combustion chamber. Viscosity of oil was measured using Ostwald's viscometer in which the sample was allowed to flow from the etched mark $\mathrm{X}-\mathrm{Y}$ through the capillary of the viscometer. Viscosity was calculated as: $n_{1} / n_{2}=d_{1} t_{1} / d_{2} t_{2}$, where $d_{1}$ is the density of oil, $d_{2}$ the density of water, $t_{1}$ the time of flow for oil, $t_{2}$ the time of flow for water, $n_{1}$ the viscosity of oil, and $n_{2}$ the viscosity of water.

Free fatty acid content: It has a significant effect on the transesterfication of glycerides with alcohol using catalyst. For determining free fatty acid (FFA) content, $25 \mathrm{~mL}$ of methanol was added to $1.5 \mathrm{~g}$ of each oil sample contained in the flask; the mixture was brought to boil in a water bath and then cooled. Two drops of phenolphthalein was added to the solution. 0.1 $\mathrm{N} \mathrm{NaOH}$ was used to titrate the mixture with shaking for proper mixing.

$$
\text { FFA }[\%]=\mathrm{V} \times 0.0282 \times 100 / \text { weight of sample }
$$

Iodine value: The unsaturated fatty acid residues of the glycerides react with iodine, and the iodine value indicates the degree of unsaturation of the fatty acid residues of the glycerides. One gram of fat sample was taken in a stoppered bottle and $25 \mathrm{~mL}$ of Wij's solution was added to it. It was mixed properly and allowed to stand for $1 \mathrm{~h}$. A blank was prepared with chloroform. With $50 \mathrm{~mL}$ distilled water the stopper and neck of the flask were rinsed thoroughly. Ten milliliters of KI solution was added to it. Then it was titrated with standard sodium thiosulphate (y) till it turned pale yellow. After that few drops of starch solution was added and titrated till blue colour disappears. The steps were repeated with a blank which did not contain any fat sample (x).

Saponification value: Saponification value indicates the presence of normal triglycerides, which can be used for production of liquid soap and shampoo. For determining saponification value, $1 \mathrm{~g}$ of oil sample was taken in different conical flasks and $3 \mathrm{~mL}$ of fat solvent was added to each flask. Twenty-five millilitres of ethanol potash was added and refluxed for 30 min with frequent shaking. After cooling, two drops of phenolphthalein 
indicator was added to each flask and titrated with $0.5 \mathrm{M} \mathrm{HCl}(\mathrm{x})$ with vigorous shaking without delay to get the end point. The step was repeated for a blank which did not contain oil sample (y).

\section{Saponification value $=28.05 \times$ Titre value $(x-y) /$ weight of sample $(g)$}

\section{RESULT AND DISCUSSION}

The physical properties such as 10-seed weight, oil content and biodiesel content of seeds collected from 30 different biotypes from four districts were studied (Table 1). The maximum 10-seed weight was found in seeds collected from Zaheerabad ( $7.3 \mathrm{gm})$. The oil content varied between 25 and $45 \%$. The maximum oil content was observed in seeds from Gulbarga (43\%) and minimum was found in seeds from Bidar (31.5\%) (Table 1). Higher oil content of neem indicates its suitability as a non-edible vegetable oil feedstock in oleochemical industries (biodiesel, fatty acids, soap, fatty nitrogenous derivatives, surfactants and detergents, etc.). Soil conditions play a significant role in causing variations in oil yield (Srivastava 1999). Again variation in oil yield may be due to the differences in biotype of plant, cultivation climate, ripening stage and the harvesting time of the seeds (Nzikou et al. 2009). To make biodiesel from neem oil, the base-catalysed transesterification was selected as the process and methyl esters were obtained in the range of $60-85 \%$. Gulbarga seeds were found to have maximum biodiesel content $(85 \%)$ and minimum was obtained in seeds from Bidar (60\%) (Table 1).

The characteristic of oil properties such as relative density, viscosity, iodine value, free fatty acid content and saponification value are presented in Table 2 and illustrated in figure 1 to 5 .

Density of oil ranged from 0.86 to $0.96 \mathrm{~g} / \mathrm{cm} 3$. Oil extracted from seeds of Bidar was found to have highest density $(0.92 \mathrm{~g} / \mathrm{cm} 3)$, whereas that from Raichur had lowest density $\left(0.89 \mathrm{~g} / \mathrm{cm}^{3}\right)$ (Table 2). The density of neem oil was found to be higher than diesel. Higher density means more mass of fuel per unit volume for vegetable compared to diesel oil. The higher mass of fuel would give higher energy available for work output per unit volume.

Viscosity of oil obtained was in the range of $41.20-50.32 \mathrm{~mm}^{3} / \mathrm{sat} 30^{\circ} \mathrm{C}$. It was found to be maximum in Bidar seeds $\left(50.32 \mathrm{~mm}^{3} / \mathrm{s}\right)$ and minimum in Raichur seeds $\left(41.20 \mathrm{~mm}^{3} / \mathrm{s}\right)$ (Table 2). Higher viscosity of biodiesel as fossil diesel implies that biodiesel has a lubricating effect in engines which will be an added advantage to the users, since it will reduce wear and tear in the engine.

FFA, the major factor for determination of oil quality for biodiesel formation, was found to be maximum in case of Bidar seeds $(4.50 \%)$ and minimum in Gulbarga seeds $(1.015 \%)$ (Table 2). The high FFA content $(>2 \% \mathrm{w} / \mathrm{w})$ favours soap formation and the separation of products will be exceedingly difficult and, as a result, it has low yield of the biodiesel product (Crabbe et al. 2001).

The saponification value of oil extracted was determined and found to be in the range of 180-191g. Maximum saponification value was found in Zaheerabad seeds (190.84 g) and minimum in Gulbarga seeds (180.54 g) (Table 2). The high saponification value reported in this study showed that the oil is normal triglyceride and it is very useful in the production of soap and shampoo (Akbar et al. 2009).

High iodine value ( $81.28 \mathrm{mg} / \mathrm{g}$ in Bidar seeds) shows high unsaturation of the oil. The limitation of unsaturation of fatty acid is vital due to the fact that heating highly unsaturated fatty acids results in polymerisation of glycerides which could lead to the formation of deposits. 
Table 2. The Physico chemical properties of Neem oil.

\begin{tabular}{|c|c|c|c|c|}
\hline \multirow{2}{*}{ Parameters } & \multicolumn{4}{|c|}{ Neem oil } \\
\cline { 2 - 5 } & Bidar & Gulbarga & Raichur & zaheerabad \\
\hline Density (gm/ml) & 0.92 & 0.90 & 0.89 & 0.91 \\
\hline Viscosity (cST) & 50.32 & 43.75 & 41.20 & 48.29 \\
\hline Iodine Value & 81.28 & 77.53 & 78.89 & 80.64 \\
\hline Free fatty acid content & 3.15 & 1.015 & 4.50 & 2.256 \\
\hline Saponification value & 188.10 & 180.54 & 186.20 & 190.84 \\
\hline
\end{tabular}

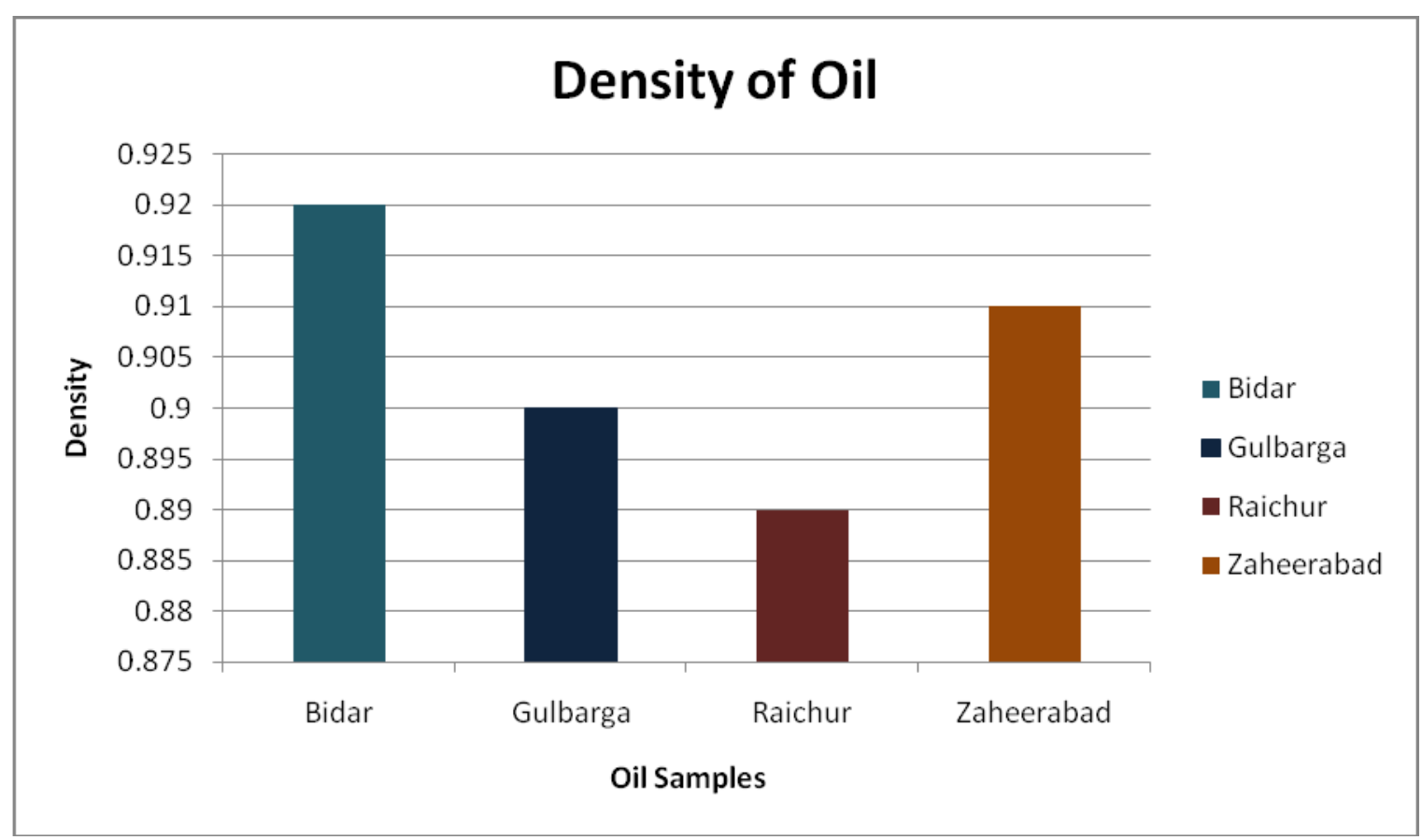

Fig. 1. Density of Oil Samples from different area. 


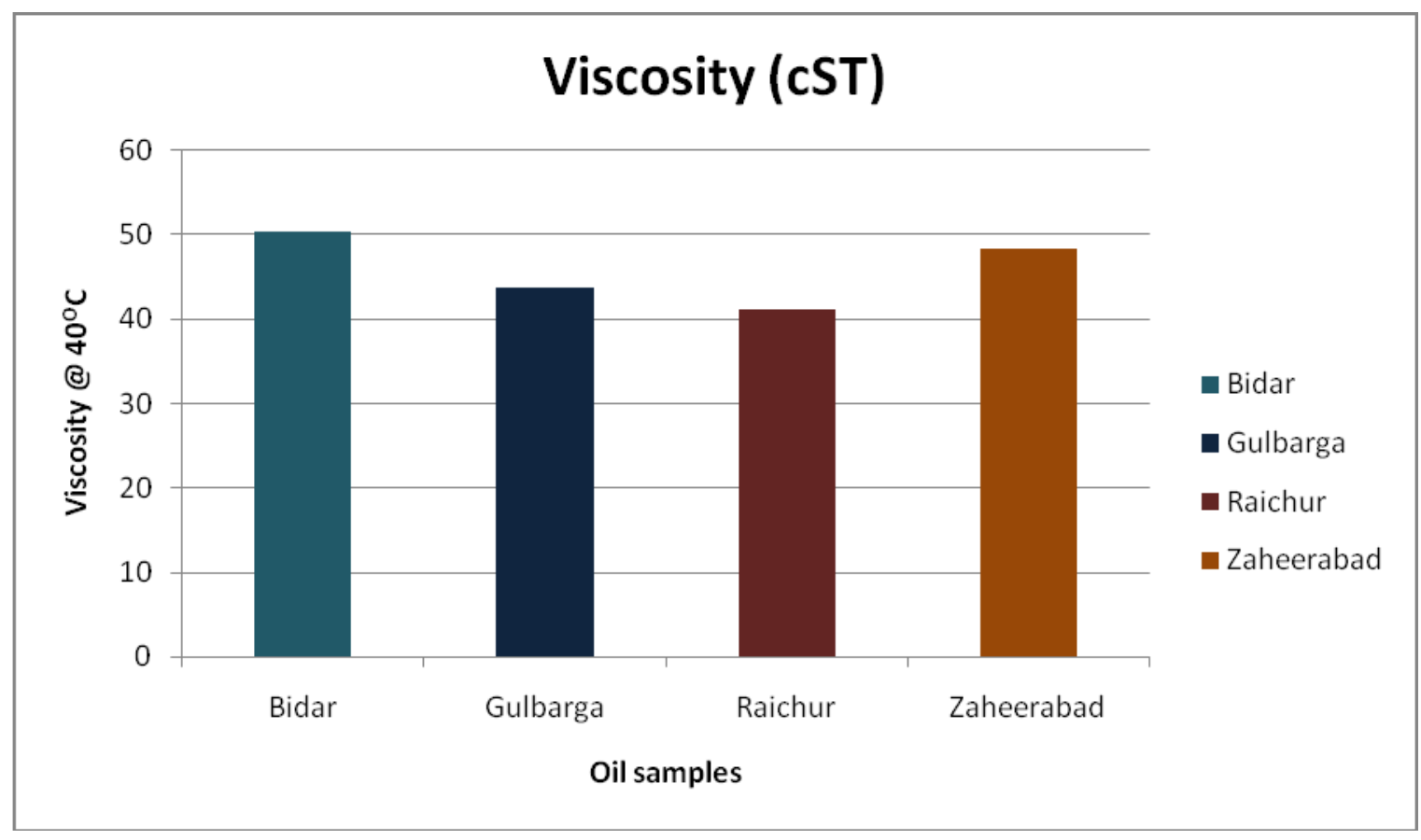

Fig. 2. Viscosity of Oil Samples from different area.

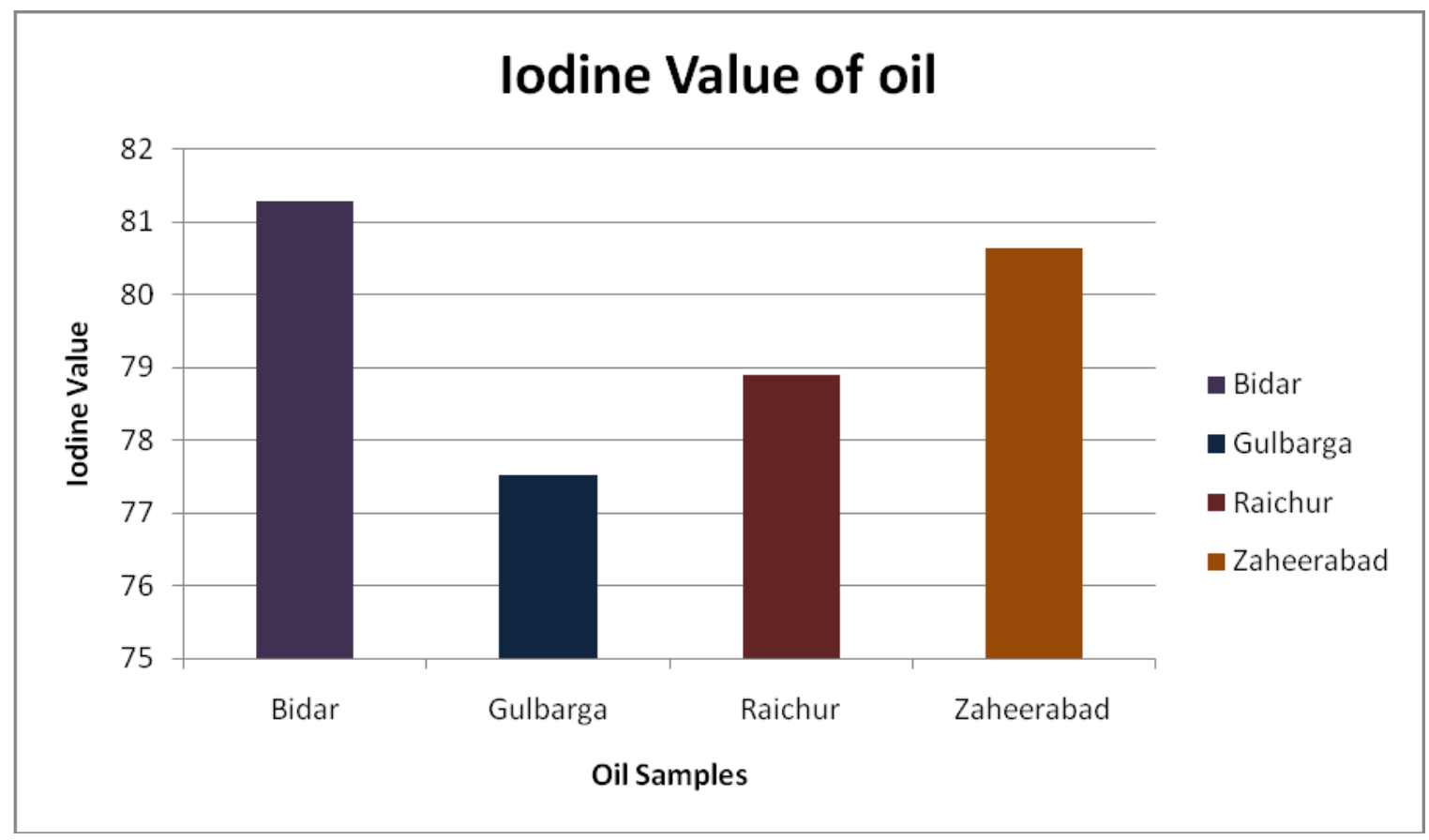

Fig. 3. Iodine Value of Oil Samples from different area. 


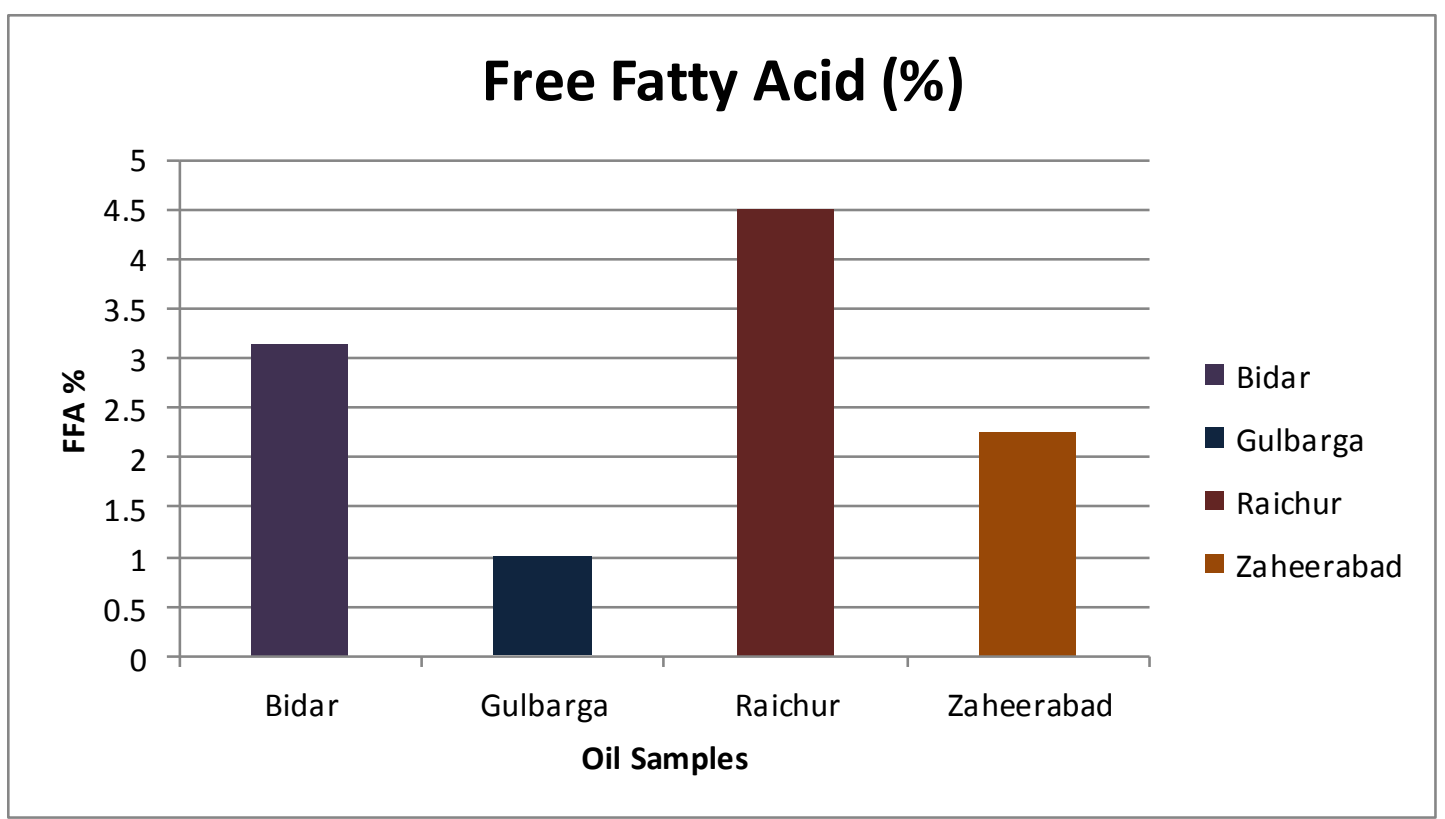

Fig. 4. Free fatty acid content of Oil Samples from different area.

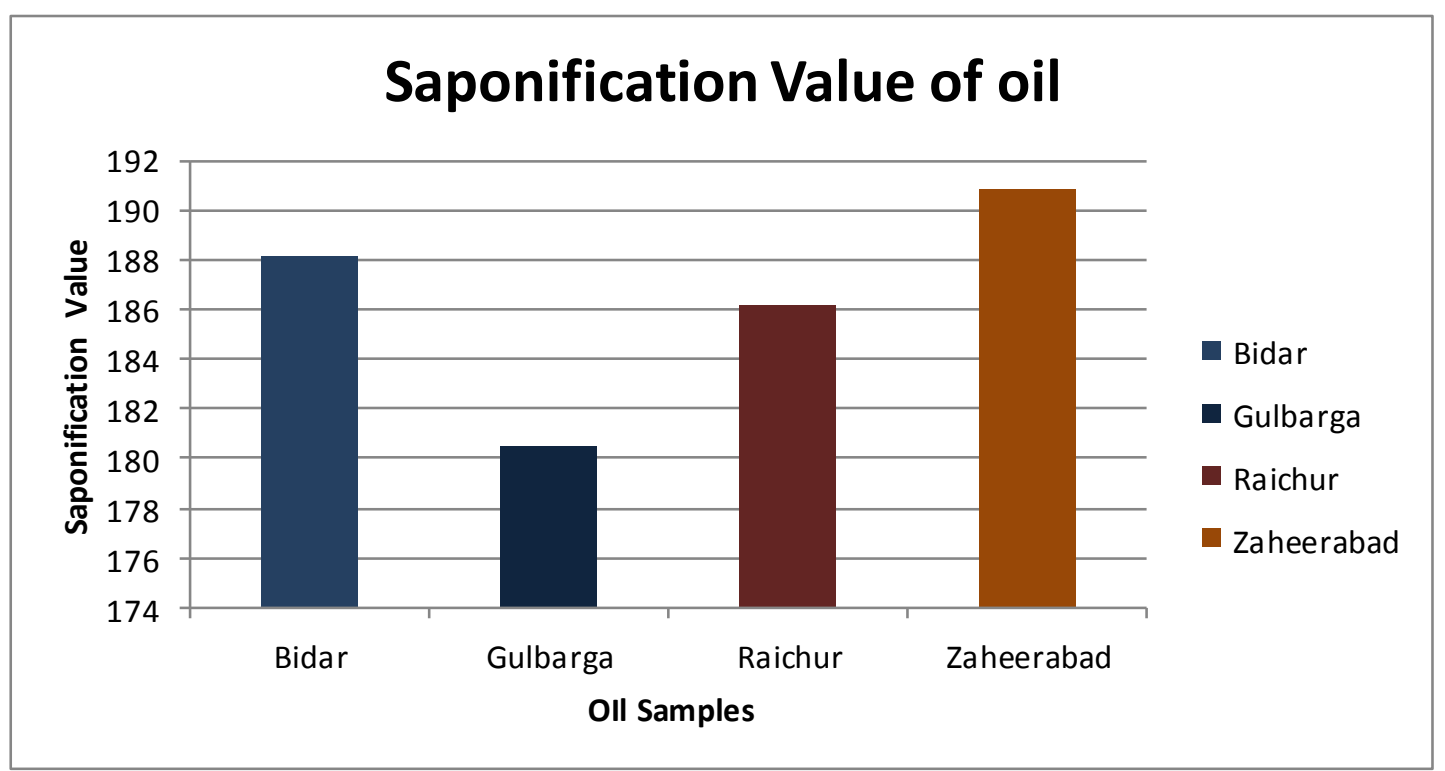

Fig. 5. Saponification value of Oil Samples from different area.

\section{CONCLUSION}

On the basis of the results obtained from all the experiments it was concluded that seeds from Gulbarga district were of better quality with respect to level of oil content, FFA content, and Saponification value. The seed sources in most of the cases were significantly different in oil yield and quality parameters, showing a considerable amount of variability within the distribution range and indicating a good scope of genetic gain through selection. The present study also confirmed that considerable genetic variability exists in neem with respect to oil content and oil quality parameters, which offers scope to the breeder for selection and 
breeding and it also shown that the neem oil can be used as raw materials to obtain biodiesel fuel of high quality and could be suitable alternative to fossil diesel. Further research is essential to enhance the knowledge base for genetic improvement in neem for quality oil production which could be used in biodiesel production.

\section{Acknowledgment}

The authors are grateful to Department of Biotechnology, Government of India, New Delhi for the financial assistance.

\section{References}

[1] Akbar E Z, Yaakub S K, Kamarudin M Ismail and J Salimon, European Journal of Scientific Research 29(3) (2009) 396-403.

[2] Crabbe E C N, Nolasco-Hipolito G, Kobayashi K Sonomoto and A Ishizaki, Process Biochemistry 37(1) (2001) 65-71.

[3] Crentsil Kofi Bempah, Archibold Buah-Kwofie and Jacob Asomaning, Elixir Appl. Botany 39 (2011) 4951-4953.

[4] Demirbas A, Prog. Energy Combust Sci. 33(1) (2007) 1-18.

[5] Jidon Janaun and Naoko Ellis. Renewable and Sustainable Energy Reviews 14 (2010) 1312-1320.

[6] K C Verma, Nisha Juneja, International Journal of Sustainable Energy 33(4) (2014) 946-953.

[7] M Mohibbe Azam, Amtul Waris and N M Nahar, Biomass and Bioenergy 29 (2005) 293-302.

[8] Muthu H, SathyaSelvabala V, Varathachary T, Kirupha Selvaraj D, Nandagopal J, Subramanian S, Braz. J. Chem. Eng. 27(4) (2010) 601-608.

[9] Nzikou J M, L Matos, F Mbemba, C B Ndangui, N P G Pambou-Tobi, A Kimbonguila, T Silou, M Linder and S Desobry, Research Journal of Applied Sciences, Engineering and Technology 1(3) (2009) 154-159.

[10] Ragit S S, Mohapatra S K, Kundu K, Gill P, Biomass Bioenergy 35(3) (2011) 11381144.

[11] Singh P K, A K Kumar, S Sethi, http://dspace.nitrkl.ac.in/dspac. (2006).

[12] Srivastava R, Forest Research Institute (Deemed University), Dehradun (1999).

[13] Vuppaladadiyam V. K, Sangeetha C J, Sowmya V, Universal Journal of Environmental Research and Technology 3(1) (2013) 113-118. 